\begin{tabular}{|c|l|}
\hline Title & A tmospheric response to interannual variability of sea surface temperature front in the East China Sea in early summer \\
\hline Author(s) & Sasaki, Y oshi N; Y amada, Y uko \\
\hline Citation & $\begin{array}{l}\text { Climate Dynamics, 51/7-8), 2509-2522 } \\
\text { https://doi.org/40.1007/300382-017-4025-y }\end{array}$ \\
\hline Issue Date & 2018 10 \\
\hline Doc URL & http://hdl.handle.net/2115/75604 \\
\hline Rights & The final publication is available at link.springer.com \\
\hline Type & article (author version) \\
\hline File Information & Clim Dyn.pdf \\
\hline
\end{tabular}

Instructions for use 


\title{
Atmospheric response to interannual variability of sea surface temperature front in the East China Sea in early summer
}

\author{
Yoshi N. Sasaki and Yuko Yamada
}

Faculty of Science, Hokkaido University, Sapporo, Japan

doi: $10.1007 / \mathrm{s} 00382-017-4025-\mathrm{y}$

Accepted in Climate Dynamics on 24 November 2017

Corresponding author address: Yoshi N. Sasaki, Science 8th bldg, 8-3-20, Faculty of Science, Hokkaido University, N10, W8, Sapporo, 060-0810, Japan.

E-mail: sasakiyo@sci.hokudai.ac.jp 


\begin{abstract}
The atmospheric response, especially the response of the meiyu-baiu rainband, to interannual variability of the sea surface temperature (SST) front associated with the Kuroshio in the East China Sea in early summer is examined by using reanalysis, satellite, and rain-gauge datasets from 1982 to 2010. It is revealed that the strong (weak) SST front in the East China Sea is accompanied by the heavy (weak) precipitation over the central East China Sea and the southern Japan. Because the strong SST front largely results from the negative SST anomaly over the continental shelf, the local evaporation change in the East China Sea is not balanced by this enhanced precipitation. The moisture for this enhanced precipitation is supplied by interannual variability of horizontal wind convergence over the central East China Sea. In addition to the precipitation change, the strong SST front is also accompanied by the intensification of weather disturbances in the lower troposphere over the East China Sea. This is probably because the negative SST anomaly over the continental shelf enhances the baroclinicity in the lower troposphere. This intensification of the weather disturbances over the East China Sea can explain the enhanced precipitation over the central East China Sea in response to the interannual variability of the SST front. Because the SST anomaly over the continental shelf, which primarily determines the interannual variability of the SST front, persists for a couple of months, these results imply the predictability of the precipitation associated with the meiyu-baiu rainband.
\end{abstract}




\section{Introduction}

The advent of satellite observations and high resolution numerical simulations reveal significant impact of sea surface temperature (SST) fronts associated with warm western boundary currents, such as the Gulf Stream and the Kuroshio, on the atmosphere through heat and moisture exchanges (e.g., Chelton et al. 2004; Liu et al. 2007; Minobe et al. 2008; Small et al. 2008; Kelly et al. 2010). The responses to the SST fronts in the mean states are seen not only in a marine atmospheric boundary layer, such as surface wind, but also in the free atmosphere, such as precipitation and synoptic weather disturbances over the SST fronts (e.g., Nakamura et al. 2008; Minobe et al. 2008; Joyce et al. 2009; O'Neill et al. 2010). Interestingly, these effects of the SST fronts indicate substantial seasonal differences (Minobe et al. 2010). In winter seasons, the atmospheric response to the SST fronts is relatively confined within a marine atmospheric boundary layer (e.g., Xie et al. 2002; Tokinaga et al. 2009; Masunaga et al. 2015). On the other hand, the summertime atmospheric response extends to the upper troposphere through deep atmospheric convection (e.g., Minobe et al. 2010; Sasaki et al. 2012).

Interannual to decadal variability of the SST fronts also influences atmosphere, although the number of studies are fewer compared to the atmospheric response in the mean states. Similar to the mean states, interannual to decadal variability of the SST fronts influences precipitation (e.g., Hand et al. 2014) and weather disturbance activities (e.g., Joyce et al. 2009; Nakamura et al. 2012; Taguchi et al. 2012) over the SST fronts. Nevertheless, previous studies generally focused on atmospheric response in winter seasons (e.g., Frankignoul et al. 2011), but little attention has been paid to the atmospheric response in summer seasons. O'Reilly and Czaja (2014) examined the atmospheric response of storm track to interannual to decadal variability of the SST front in the Kuroshio Extension region, but the corresponding response is weak in summer. Nakamura and Yamane (2010) showed relationships of the surface baroclinicity variability on interannual timescales in the Kuroshio-Oyashio Extension region to the SST front and also to storm tracks in summer seasons, but they did not show the direct relationship between the SST front and storm track fluctuations. Therefore, the purpose of the present study is to clarify summertime atmospheric response to interannual variability of a SST front.

To this end, we focus on the SST front associated with the Kuroshio in the East China Sea (Fig. 1), a marginal sea east of China and west of the Ryukyu Islands. The reason to focus on this region is that the summertime atmospheric response to the SST front in the mean states is prominent along with the Gulf Stream region (Sasaki et al. 2012). The Kuroshio, the western boundary current of the subtropical gyre in the North Pacific, transports large amount of heat poleward (Figs. 1b and 2). There is a SST front between the warm water of the Kuroshio and the cold water over the continental shelf (Xie et al. 2002; Kida et al. 2015; Fig. 1a-b). In the mean state, the atmospheric response characterized by enhanced precipitation over the warm SSTs of the Kuroshio is seen in 
early spring and summer (Xu et al. 2011; Sasaki et al. 2012; Liu et al. 2016; Xu et al. 2017), especially in June. This is because a large-scale rainband, the so-called meiyu-baiu rainband, covers the East China Sea in June (Figs. 1c and 3). The meiyu-baiu rainband is accompanied by strong gradients of specific humidity and thus equivalent potential temperature in the lower troposphere, and has been investigated by many studies (e.g., Akiyama 1975; Ninomiya 1984; Kato 1998; Kwon et al. 2005; Tomita et al. 2010b; Sampe and Xie 2010; Yim et al. 2015; Kawai et al. 2017). However, the atmospheric response, especially the response of the meiyu-baiu rainband, to interannual variability of the SST front in the East China Sea has not been investigated, yet. Hence, we will examine the atmospheric response to interannual variability of the SST front in the East China Sea in early summer.

The rest of the present paper is organized as follows. In section 2, we describe the datasets and methods for investigating the atmospheric response to interannual variability of the SST front in the East China Sea. The interannual variability of the SST front and associated oceanic fluctuations are described in section 3, and the corresponding atmospheric response, especially precipitation and weather disturbances, is examined in section 4. A summary and discussion are presented in section 5.

\section{Data and method}

To obtain interannual variability of the SST front in the East China Sea, we use monthly SST data of the version 2 of the optimum interpolation SST product (OISSTv2; Reynolds et al. 2007) from 1982 to 2010 provided by the National Oceanic and Atmospheric Administration (NOAA). This OISSTv2 dataset has a $0.25^{\circ} \times 0.25^{\circ}$ grid and uses in situ and the Advanced Very High Resolution Radiometer SST data. The atmospheric dataset mainly used in this study is 6-hour forecast fields of the National Centers for Environmental Prediction Climate Forecast System Reanalysis (NCEPCFSR) product (Saha et al. 2010). We employ 6-hourly data at a $0.5^{\circ} \times 0.5^{\circ}$ spatial resolution with 37 vertical levels from 1982 to 2010 . Note that the ocean model of the NCEP-CFSR reanalysis product assimilates the high-resolution SST values of the OISSTv2 product. In addition to the NCEP-CFSR reanalysis product, to investigate the consistency of atmospheric response in complementary data, we also use three precipitation datasets and two surface heat flux datasets. One precipitation dataset is a Tropical Rainfall Measuring Mission (TRMM) 3B43 product derived from the TRMM satellite and other observations. This dataset is available after January 1998 on a $0.25^{\circ} \times 0.25^{\circ}$ grid at monthly intervals (Huffman et al. 2007). The second dataset is the TRMM3A25 product after 1998 on a $0.5^{\circ} \times 0.5^{\circ}$ grid downloaded from https://pmm.nasa.gov/data-access/downloads/trmm. This dataset provides near surface monthly convective and stratiform precipitation. The third precipitation dataset is an APHRO-JP dataset, based on rain-gauge observations over Japan islands with a $0.05^{\circ} \times 0.05^{\circ}$ horizontal resolution from 1982 to 2010 (Kamiguchi et al. 2010). The 
monthly surface shortwave, longwave, and sensible and latent heat flux data are the Japanese Ocean Flux dataset version 2.1 on a $1^{\circ} \times 1^{\circ}$ horizontal grid from 1988 to $2008(\mathrm{~J}-$ OFURO; Tomita et al. 2010a) and the OAFlux product on a $1^{\circ} \times 1^{\circ}$ horizontal grid from 1984 to 2009 (Yu et al. 2008).

To measure the strength of the SST front associated with the Kuroshio, we define an index as the normalized difference of the area-averaged SSTs between over the Kuroshio (red in Fig. 2) minus over the continental shelf (blue in Fig. 2) in June. Hence, a positive (negative) value of this index indicates the strong (weak) SST front. The resultant index from 1982 to 2010, which we refer to as the SST front index hereafter, shows substantial interannual variability with a maximum in 2010 (Fig. 4). Note that the standard deviation of the SST front index before normalization is $0.47^{\circ} \mathrm{C}$. Correlation and regression analyses using the SST front index are conducted to examine the atmospheric response to the interannual variability of the SST front. The statistical significance of correlation coefficients is based on Student's t-test, where monthly mean values in each year are treated as statistically independent. Our results are robust if the data are detrended or high-pass filtered $(<10$-yr) before calculating the correlation and regression coefficients.

\section{Oceanic variability}

Before investigating the atmospheric response to the interannual variability of the SST front, we examine the corresponding variability of ocean and air-sea heat exchange in the East China Sea in this section. The regression coefficients of SST in June on the SST front index show the negative SST anomaly with a maximum of $-0.8^{\circ} \mathrm{C}$ over the continental shelf of the East China Sea (Fig. 5a). In contrast, a significant SST anomaly is not seen along the Kuroshio path. Consistently, the SST front index is well correlated to the SST variability averaged over the continental shelf $(r=-0.80)$, while these two time series are not identical. This indicates that the interannual variability of the strength of the SST front is mainly determined by the SST variability over the continental shelf. Indeed, the interannual standard deviation of SST averaged over the continental shelf $\left(0.62^{\circ} \mathrm{C}\right)$ is larger than that averaged over the Kuroshio $\left(0.37^{\circ} \mathrm{C}\right)$. This difference of the amplitude is probably because the heat content of a water column over the continental shelf, which is roughly proportional to the bottom depth (Xie et al. 2002), is smaller than that in the Kuroshio axis region (see Fig. 1a). Thus, the smaller heat content makes it easier to vary the SST. This different nature of the SST variability between the continental shelf and the Kuroshio regions results in the variability of the SST front strength.

To compare the SST front index with dominant SST variability in the East China Sea, an Empirical Orthogonal Function (EOF) analysis for SST is performed in the East China Sea $\left(24^{\circ} \mathrm{N}-36^{\circ} \mathrm{N}, 120^{\circ} \mathrm{E}-131^{\circ} \mathrm{E}\right)$. The principal component of the first EOF mode, which explains $39.1 \%$ of the total SST variances, is well correlated to the SST front index 
( $r=0.78$; statistically significant at $90 \%$ confidence level). Consistently, the spatial pattern of this first mode shows a monopole SST anomaly over the continental shelf (not shown). This result indicates that the SST front index is partly related to the dominant SST variability in the East China Sea.

The corresponding surface net heat flux (the sum of shortwave, longwave, and sensible and latent heat fluxes) shows the downward net heat flux anomaly over the continental shelf (Fig. 6a), although the J-OFURO dataset is only available from 1988 to 2008. The co-location of this downward heat flux and the negative SST anomaly over the continental shelf means that the negative SST anomaly cools the atmosphere. Note that the net heat flux anomaly of the OAFlux product from 1984 to 2009 also shows the negative anomaly over the continental shelf, while the corresponding correlation coefficients are not statistically significant (not shown). If we computed separately for each surface heat flux component, the negative heat flux anomaly over the continental shelf is largely attributed to the latent heat flux change (Fig. 6b). That is, the strong (weak) SST front is accompanied by the decreasing (increasing) of the evaporation over the continental shelf. We further checked the surface latent heat flux anomaly of the NCEP-CFSR product from 1982 to 2010 and found that the corresponding spatial pattern is similar, although its amplitude is somewhat smaller than Fig. 6b (not shown).

When is the negative SST anomaly over the continental shelf in June formed? Interestingly, a similar negative SST anomaly is already located over the continental shelf in May (Fig. 5b). The amplitude of this SST anomaly is also comparable to that in June. On the other hand, the negative SST anomaly over the continental shelf in April has weaker amplitude and a lesser spatial extent than that in May and in June (Fig. 5c). We also examined the SST anomaly in February and in March, and found that the negative SST anomaly over the continental shelf becomes smaller and weaker in March and almost disappeared in February (not shown). Hence, these results suggest that the SST anomaly over the continent shelf in June is likely formed during early spring (FebruaryApril). We also examined the corresponding surface heat flux change from February to May by using the J-OFURO dataset. In May, similar anomalous downward net heat flux to the anomaly in June shown in Fig. 6a is seen over the continental shelf (not shown), but its amplitude is about half of the anomalous heat flux in June and the corresponding correlation coefficients are statistically insignificant. In addition, significant heat flux anomalies are not seen over the continental shelf from February to April. These results are consistent with the above result that the SST anomaly over the continental shelf is formed in early spring. We speculate that the SST anomaly over the continental shelf might be caused by wintertime atmospheric cooling (Xie et al. 2002) or by the influence of Yangtze River discharge (e.g., Kako et al. 2016), but the detailed mechanism is beyond the scope of this study.

\section{Atmospheric response}




\subsection{Precipitation}

In the previous section, we showed that the interannual variability of the SST front strength in the East China Sea in June is mainly determined by the SST variability over the continental shelf. In addition, when the SST front is strong (weak), the negative (positive) SST anomaly over the continental shelf cools (warms) the atmosphere. In this section, the atmospheric response to the interannual variability of the SST front strength is examined. First, we investigate the response of precipitation.

The regression coefficients of the precipitation rate of the NCEP-CFSR product onto the SST front index show positive precipitation anomalies over the central East China Sea and the southern Japan with the axis tilted from southwest to northeast (Fig. 7a). This location roughly corresponds to the northern part of the climatological meiyubaiu rainband (Fig. 1c). That is, the strong SST front intensifies the meiyu-baiu rainband over the East China Sea. Except for these positive precipitation anomalies, the negative precipitation anomalies are located over the south of Taiwan and the south of Japan. Note that if we alternatively use the absolute SST time series over the continental shelf region (Fig. 1b), the corresponding precipitation anomaly over the East China Sea is much weaker (not shown). Recalling that the strong SST front is associated with the decreasing of the evaporation over the continental shelf (Fig. 6b), the strong SST front is paradoxically accompanied by the positive precipitation anomaly aloft. This is likely consistent with Fujibe (2015), who found negative correlations between interannual variability of precipitation over western Japan and interannual SST variability in the surrounding area in summer. In contrast, in regional atmospheric model simulations, a prescribed positive SST anomaly in the East China Sea in summer generally enhances the precipitation (e.g., Sasaki et al. 2012; Manda et al. 2014). This point will be discussed later in this subsection by using the moisture budget analysis.

A similar precipitation anomaly pattern to the reanalysis product is seen from the satellite and rain-gauge datasets. The regression coefficients of the precipitation rate of the TRMM3B43 product from 1998 to 2010 to the SST front index also show the positive precipitation anomaly over the central East China Sea and the southern Japan (Fig. 7b). However, the peak of this precipitation anomaly is located over the southern Japan, which is different from the precipitation change in the NCEP-CFSR product (Fig. 7a). This discrepancy is due to the difference of the data periods. The regression coefficients of the precipitation in the NCEP-CFSR product before and after 1998 to the SST front index exhibit a peak over the central East China Sea and the southern Japan, respectively (Fig. $7 d-e)$.

This large precipitation anomaly over the southern Japan in the reanalysis and the satellite datasets is also consistent with the precipitation anomalies of the rain-gauge base dataset (Fig. 7c). The amplitude of the rain-gauge base dataset is also similar with that of the satellite data. As an example of the precipitation change at a rain-gauge station, Figure 8 shows the precipitation of the rain-gauge station at Uchinoura $\left(31.278^{\circ} \mathrm{N}\right.$, 
$131.075^{\circ} \mathrm{E}$; see also Fig. 1c) in June along with the SST front index. The precipitation at this station is well correlated to the SST front index $(\mathrm{r}=0.63$; statistically significant at $90 \%$ confidence level). These two time series reach the highest values in 2010 . Therefore, the response of the precipitation to the interannual variability of the SST front is confirmed from the satellite and rain-gauge observations. It is noting that a visual inspection of Fig. 8 suggests that the relationship between the two time series seems to be stronger during the latter half of the data period than during the first half. Indeed, the correlation of the latter half is much higher than that of the first half ( $r=0.92$ vs. $r=$ 0.29). This is consistent with the aforementioned shift of the peak location of the precipitation anomalies associated with the data period difference (Fig. 7).

The precipitation rate of the NCEP-CFSR reanalysis dataset can be separated into convective precipitation rate and large-scale precipitation rate. Thus, it is informative to clarify which component is more important for the precipitation response to the SST front strength. The positive precipitation anomaly over the central East China Sea and the southern Japan largely comes from the large-scale precipitation (Fig. 9b), while both the convective and large-scale precipitation anomalies have similar spatial structures (Fig. 9a). The amplitude of the convective precipitation anomaly over the central East China Sea is about half of the large-scale precipitation. This ratio is different from that of the climatology, in which the half of the meiyu-baiu rainband over the East China Sea in June is convective precipitation (Sasaki et al. 2012). We also examined the response of convective and stratiform precipitations by using the TRMM3A25 data from 1998 to 2010, and consistently found that the stratiform precipitation anomaly is much larger than the convective precipitation anomaly over the southern Japan (not shown).

From a viewpoint of the moisture budget, the positive precipitation anomaly over the central East China Sea shown in Fig. 7a is not balanced to the local evaporation change (Fig. 6b). This implies that horizontal moisture convergence is expected to play a dominant role in supplying the moisture over the central East China Sea. To test this idea, the moisture flux convergence is estimated from the 6-hourly NCEP-CFSR reanalysis product as follows (e.g., Smith et al. 2010):

$$
\text { moisture flux convergence } \equiv-\frac{1}{\rho g} \int_{P_{\text {top }}}^{P_{s}} \nabla_{h} \bullet q \mathbf{u} d p
$$

where $q$ is specific humidity, $\rho$ is density of water, $p$ is pressure, $P_{s}$ is surface pressure, $P_{\text {top }}$ is set as $100 \mathrm{hPa}, \mathbf{u}$ is horizontal wind vector, $g$ is the acceleration of gravity, and $\nabla_{h}$ is the horizontal divergence operator. As expected, the spatial structure of the moisture flux convergence change (Fig. 10a) closely resembles that of the precipitation change (Fig. 7a). Therefore, the moisture supplied by the moisture flux convergence change is balanced to the sum of the positive precipitation anomaly and the decreasing of the evaporation over the central East China Sea and the southern Japan.

To examine the moisture flux convergence change in further detail, the right hand side in the equation (1) is separated into two terms as follows: 


$$
-\frac{1}{\rho g} \int_{P_{\text {top }}}^{P_{s}} \nabla_{h} \bullet q \mathbf{u} d p=-\frac{1}{\rho g} \int_{P_{\text {top }}}^{P_{S}} q \nabla_{h} \cdot \mathbf{u} d p-\frac{1}{\rho g} \int_{P_{\text {top }}}^{P_{S}} \mathbf{u} \bullet \nabla_{h} q d p .
$$

In the right hand side, the first term represents the moisture convergence by the horizontal wind convergence and the second term represents the horizontal advection of specific humidity. As a result of this separation, we found that the moisture flux convergence by the horizontal wind convergence is dominant for the moisture convergence change over the central East China Sea (Fig. 10b), which is similar to the climatological moisture budget of the meiyu-baiu rainband over the East China Sea (Xu et al. 2017). The horizontal advection of specific humidity plays a minor role.

Since we focus on the interannual variability of the horizontal wind convergence, the first term in the right hand side in the equation (2) can be further separated into four terms as follows:

$-\frac{1}{\rho g} \int_{P_{\text {top }}}^{P_{s}} q \cdot \nabla_{h} \mathbf{u} d p=-\frac{1}{\rho g} \int_{P_{\text {top }}}^{P_{s}} \bar{q} \cdot \nabla_{h} \overline{\mathbf{u}} d p-\frac{1}{\rho g} \int_{P_{\text {top }}}^{P_{s}} \bar{q} \cdot \nabla_{h} \mathbf{u}^{\prime} d p-\frac{1}{\rho g} \int_{P_{\text {top }}}^{P_{s}} q^{\prime} \cdot \nabla_{h} \overline{\mathbf{u}} d p-\frac{1}{\rho g} \int_{P_{\text {top }}}^{P_{s}} q^{\prime} \cdot \nabla_{h} \mathbf{u}^{\prime} d p,(3)$

where the overbar denotes the monthly climatology and the prime denotes the anomaly from the monthly climatology. After ignoring the first and fourth terms in the right hand side in the equation (3), the comparison between the contributions of the second and third terms indicates that the second term is dominant (Fig. 10c). Hence, the horizontal wind convergence variability on interannual timescales induces the enhancement of the precipitation over the central East China Sea and the southern Japan. Interannual variability of the specific humidity over the East China Sea is not important for the enhanced precipitation. The interannual variability of the horizontal wind convergence will be reexamined in the subsection 4.3.

\subsection{Weather disturbance}

The response of weather disturbances over the East China Sea to the interannual variability of the SST front strength is examined in this subsection. As mentioned in introduction, previous studies showed interannual to decadal fluctuations of the SST fronts influence wintertime weather disturbances (e.g., Joyce et al. 2009; O'Reilly and Czaja 2014). Isobe and Kako (2012) showed that the climatological SST front in the East China Sea in winter plays an important role in the development of extratropical cyclones. Furthermore, weather disturbances are a possible candidate for the cause of interannual variability of the horizontal wind convergence over the central East China Sea shown in Fig. 10c. To examine the response of weather disturbances, as a measure of weather disturbance activity, we employ a front intensity index $F=\zeta \nabla_{h} T \mid$ normalized by a typical scale of temperature gradient $(1 \mathrm{~K} / 100 \mathrm{~km}$ ) and the Coriolis parameter (Parfitt et al. 2016), where $\zeta$ and $T$ is relative vorticity and temperature, respectively. Parfitt et al. (2016) employed this index to capture atmospheric fronts over the North Atlantic in winter by using a certain threshold (i.e., $F \geq 1$ ). Although Parfitt et al. (2016) used 
Coriolis parameter at $40^{\circ} \mathrm{N}$, we use the value at $30^{\circ} \mathrm{N}$ to consider the difference of the study area. Following Parfitt et al. (2016), we estimated $F$ at $925 \mathrm{hPa}$ (hereafter F925). Note that because F925 mainly captures atmospheric fronts, we consider not the all but a significant part of storm track change.

Before investigating the change of F925, we show its monthly climatology estimated from the 6-hourly NCEP-CFSR reanalysis data (Fig. 11a), where we do not use a threshold of F925 for simplicity. The positive (cyclonic) values of F925 extend from over the southwest coast of China to over the southern Japan across the East China Sea. Note that this positive band is collocated with the climatological meiyu-baiu rainband over the East China Sea (Fig. 1c), consistent with previous studies showing the importance of weather disturbances in the formation of the meiyu-baiu rainband (e.g., Ninomiya and Shibagaki 2003; Sampe and Xie 2010). Relatively large values of F925 over coastal areas are probably due to surface temperature contrast between the land and ocean.

Interannual variability of the weather disturbances is related to the interannual variability of the SST front strength. The regression coefficients of F925 onto the SST front index exhibit the positive anomalies from over the southwest coast of China to over the southern Japan across the central East China Sea (Fig. 11b). This band-like structure of the F925 anomalies suggests that the weather disturbances along this pathway are intensified (weakened), when the SST front is strong (weak). This result is robust, even if we use $|\zeta|$ at 925 (i.e., square root of the enstrophy) as a measure of weather disturbances (not shown). Interestingly, these positive F925 anomalies are co-located with the positive precipitation anomalies (Fig. 7a). Indeed, interannual fluctuations of F925 averaged over the central East China Sea $\left(28^{\circ} \mathrm{N}-31^{\circ} \mathrm{N}, 123^{\circ} \mathrm{E}-128^{\circ} \mathrm{E}\right)$ are well correlated with those of the precipitation $(r=0.70)$. This relation will be further examined in the next subsection.

The positive correlation between the strength of the SST front and the intensity of the weather disturbances implies the importance of surface baroclinicity change of the background atmospheric state over the East China Sea. To investigate the surface baroclinicity change, we estimate the Eady growth rate $\sigma$ from the monthly NCEP-CFSR reanalysis data as follows (e.g., Hoskins and Valdes 1990; Small et al. 2014):

$$
\sigma=0.31 \frac{g}{T} \frac{\left|\nabla_{h} T\right|}{N}
$$

where $N$ is buoyancy frequency. The change of the Eady growth rate at $925 \mathrm{hPa}$ associated with the SST front index shows the positive anomaly over the East China Sea (Fig. 12). This positive anomaly of the Eady growth rate is consistent with the intensification of the weather disturbances over the central East China Sea (Fig. 11b). Although, the positive anomaly of the Eady growth rate is located somewhat south of the positive F925 anomaly, this difference is likely due to the time-lag of the growth of weather disturbances along their passages. Because the climatological Eady growth rate at $925 \mathrm{hPa}$ over the southern East China Sea is about 0.5 day $^{-1}$, the corresponding growth 
timescale is about 2 days. If the moving speed of a weather disturbance is assumed to be $500 \mathrm{~km} \mathrm{day}^{-1}$, it moves about $1000 \mathrm{~km}$. This can explain the difference of the location of the anomalies of the Eady growth rate and F925.

How does the SST front variability influence the Eady growth rate? As shown in the equation (4), the Eady growth rate is related to both the horizontal temperature gradient (i.e., $\nabla_{h} T$ ) and vertical temperature gradient (i.e., $N$ ). Figure 13 shows that the horizontal atmospheric temperature gradient at $925 \mathrm{hPa}$ becomes large around the perimeter of the negative SST anomaly over the continental shelf (Fig. 5a) due to the negative temperature anomaly in the lower troposphere (not shown). This spatial pattern closely resembles the spatial pattern of the Eady growth rate change (Fig. 12). Hence, the horizontal temperature gradient change in the lower troposphere by the SST anomaly over the continental shelf is important for the positive anomalies of the Eady growth rate over the East China Sea. On the other hand, because the negative SST anomaly over the continental shelf cools atmospheric temperature in the lower troposphere, the vertical profile of atmospheric temperature over the continental shelf becomes more stable. Although this makes $N$ large and the Eady growth rate small, this vertical temperature gradient change is not important for the Eady growth rate change over the East China Sea.

\subsection{Connection between precipitation and weather disturbance}

In the previous subsection, we showed that the weather disturbances are intensified over the central East China Sea, when the SST front is strong. The spatial structure of the positive F925 anomalies resembles that of the enhancement of the precipitation and the horizontal wind convergence change (Figs. 7a and 10c). Consistently, the F925 and precipitation variations over the central East China Sea are positively correlated on interannual timescales. In this subsection, to further examine their relationship on shorter timescales, we perform a composite analysis based on the 6hourly data of the NCEP-CFSR product. To capture the events of relatively strong atmospheric fronts, the criterion of this composite is when $F 925$ at $30^{\circ} \mathrm{N}, 126^{\circ} \mathrm{E}$ exceeds 2 and takes a maximum within plus and minus 2 days. This reference point is selected because a maximum of the regression coefficients of F925 is located (Fig. 11b). By using this criterion, we found 73 events from 1982 to 2010.

Figure 14a shows the resultant composite map of F925 and sea level pressure (SLP). Consistent with Fig. 11b, the positive F925 anomalies are located over the central East China Sea with the axis titled along the northeast-southwest direction. The corresponding SLP pattern indicates the cyclonic circulation over the central East China Sea, the center of which is collocated with the maximum of the F925 anomaly. Hence, the events of the large F925 over the central East China Sea are related to the low-level cyclones. This is reasonable because F925 is a measure of weather disturbance (Parfitt et al. 2016). It is worth noting that we checked the weather charts of every 73 events, and found that only one event results from a tropical cyclone and the other events are related 
to extratropical cyclones. This implies that tropical cyclones play a lesser role in the atmospheric response to the interannual variability of the SST front.

The corresponding precipitation anomaly pattern shows that the positive anomaly extends from over the southeastern China to over the southern Japan (Fig. 14b). The aforementioned cyclone is embedded in this anomalous rainband. A careful inspection of this pattern indicates that the peak of the positive precipitation anomaly with amplitude up to $45 \mathrm{~mm}_{\text {day }}^{-1}$ is located over the central East China Sea, which is also collocated with the maximum of F925 (Fig. 14a). This collocation between the positive F925 anomaly and the precipitation anomaly indicates that the extratropical cyclones over the central East China Sea enhance the precipitation there.

Recalling that the strong SST front causes the positive anomaly of the Eady growth rate (Fig. 12), it is expected that the extratropical cyclones are intensified over this region. Indeed, the cyclonic SLP pattern is accompanied by the trough in the upper troposphere (Fig. 14c). This implies the development of the low-level cyclone through the vertical coupling (e.g., Chang et al. 1998; Shibagaki and Ninomiya 2005; Tochimoto and Kawano 2012), consistent with the aforementioned linkage between F925 and the surface baroclinicity. This development of the low-level cyclone is also consistent with the moisture convergence by the horizontal wind convergence (Fig. 10c; Tochimoto and Kawano 2012).

To further clarify the relation of these composite results to the interannual variability of the SST front, we calculate the correlation coefficient between the SST front index and the number of the events (i.e., F925>2) in each year. The resultant correlation coefficient is 0.53 (statistically significant at $90 \%$ confidence level). The corresponding regression coefficient is 0.63 . This indicates that when the SST front index is one (see Fig. 4), the number of the events of the high F925 increases 0.63 times, compared to the climatology (2.5 times per year). This result can explain the relation between the enhanced precipitation and the intensification of the weather disturbances over the central East China Sea in response to the interannual variability of the SST front strength.

\section{Summary and Discussion}

We examined the atmospheric response to the interannual variability of the SST front associated with the Kuroshio in the East China Sea in early summer (Fig. 1), when the meiyu-baiu rainband covers the East China Sea (Fig. 3). The SST front index defined by the difference of SST between over the Kuroshio minus over the continental shelf (Figs. 2 and 4) from 1982 to 2010 is employed to measure the interannual variability of the strength of the SST front. It is revealed from the reanalysis, the satellite, and the raingauge datasets that the strong (weak) SST front is accompanied by the positive (negative) precipitation anomaly over the central East China Sea and the southern Japan (Figs. 7-8). This enhanced precipitation is largely attributed to the large-scale precipitation change, 
rather than the convective precipitation change (Fig. 9). Because the strong SST front mainly results from the negative SST anomaly over the continental shelf (Fig. 5a), which are likely formed in early spring (Fig. 5b-c), the strong SST front is associated with the decrease of the evaporation over the continental shelf (Fig. 6b). Thus, the local moisture supply through the evaporation does not play a role in supplying the moisture for the enhanced precipitation over the central East China Sea. The moisture for the positive precipitation anomaly over the central East China Sea and the southern Japan is mostly supplied by the horizontal moisture convergence change, especially interannual variability of the horizontal wind convergence (Fig. 10).

Also, the strong (weak) SST front in the East China Sea is accompanied by the intensification (weakening) of the weather disturbances in the lower troposphere over the central East China Sea (Fig. 11), similar to the wintertime atmospheric response to SST front variability (e.g., O'Reilly and Czaja 2014). The enhancement of the baroclinicity in the lower troposphere over the East China Sea (Fig. 12), due to the strengthening of the horizontal temperature gradient (Fig. 13), is likely to play a large role in this intensification. This horizontal temperature gradient change is probably induced by the cooling due to the negative SST anomaly over the continental shelf (Figs. 5a and 6). The composite analysis using the 6-hourly reanalysis data revealed that the weather disturbance events that F925 is higher than the threshold (i.e., F925>2) are accompanied by low-level cyclones and the enhanced precipitation over the central East China Sea (Fig. 14). These low-level cyclones are associated with the trough in the upper troposphere (Fig. 14c), suggesting the development of the extratropical cyclones over the East China Sea. In addition, the number of the high F925 events on interannual timescales increases (decreases), when the SST front is strong (weak). This relation can account for the connection between the responses of the precipitation and weather disturbances to the SST front strength.

The SST anomaly over the continental shelf is likely formed in early spring (March-April) and persists into June (Fig. 5) because of larger oceanic heat content compared to the atmosphere. This implies that the strength of the SST front in June has predictability on seasonal timescales. Therefore, the results in the present study indicate that the information of the SST front strength is useful for the prediction of the meiyubaiu rainband variability over the central East China Sea and the southern Japan in early summer.

In the present study, we showed the atmospheric response to the local SST variability. Nevertheless, one might argue that the relation between the SST variability and the atmospheric variability in the East China Sea is due to remote influence by atmospheric teleconnections associated with SST variability in the equatorial regions (e.g., Alexander et al. 2004; Yang et al. 2007; Du et al. 2016). We have checked the regression coefficients of SST in June onto the SST front index, but have not found 
organized SST signals in the equatorial regions (not shown). This result confirms that the atmospheric response shown in this study is caused by the local processes.

An interesting question is how the future change of the atmospheric response to the SST front in the East China Sea is. Previous studies reported that the warming rate of SST in the western boundary current regions, including the Kuroshio in the East China Sea, is faster than that of the global average during the 20th century (Wu et al. 2012; Yang et al. 2016). If this holds true in future, the fast warming in the Kuroshio region results in the strengthening the SST front and thus induces the positive precipitation anomaly over the central East China Sea and the southern Japan. However, although there are some studies that focus on future atmospheric change around the East China Sea (e.g., Kawase et al. 2009; Tsunematsu et al. 2013; Ogata et al. 2017), the role of the SST front in the East China Sea has received much less attention, partly because a high-resolution ocean model is necessary to properly resolve the SST front change. Previous studies showed the importance of the horizontal resolution of the SST data to properly simulate atmospheric response to a SST front (e.g., Iizuka 2010; Ma et al. 2017). Hence, a future study using a high-resolution regional coupled model is desired for understanding future atmospheric change in response to the SST front change in the East China Sea.

\section{Acknowledgments}

We thank Profs. S. Minobe and M. Inatsu for valuable comments. We also thank three anonymous reviewers for their constructive comments on the manuscript. This research was supported by the Grant-in-Aid for Young Scientists (B) Grant Number 16K1780, which is funded by the Ministry of Education, Culture, Sports, Science, and Technology of Japan. The TRMM3A25 data were provided by the NASA/Goddard Space Flight Center. 


\section{References}

Akiyama T (1975) Southerly Transversal Moisture Flux into the Extremely Heavy Rainfall Zone in the Baiu Season. Journal of the Meteorological Society of Japan Ser II 53:304-316 doi:10.2151/jmsj1965.53.5_304

Alexander MA, Lau N-C, Scott JD (2004) Broadening the Atmospheric Bridge Paradigm: ENSO Teleconnections to the Tropical West Pacific-Indian Oceans Over the Seasonal Cycle and to the North Pacific in Summer. In: Earth's Climate. American Geophysical Union, pp 85-103. doi:10.1029/147GM05

Chang C-P, Hou SC, Kuo HC, Chen GTJ (1998) The development of an intense East Asian Summer Monsoon disturbance with strong vertical coupling. Mon Wea Rev 126:2692-2712

Chelton DB, Schlax MG, Freilich MH, Milliff RF (2004) Satellite measurements reveal persistent small-scale features in ocean winds. Science 303:978-983 doi:10.1126/science.1091901

Du Y, Li T, Xie Z, Zhu Z (2016) Interannual variability of the Asian subtropical westerly jet in boreal summer and associated with circulation and SST anomalies. Clim Dyn 46:2673-2688 doi:10.1007/s00382-015-2723-x

Frankignoul C, Sennéchael N, Kwon Y-O, Alexander MA (2011) Influence of the Meridional Shifts of the Kuroshio and the Oyashio Extensions on the Atmospheric Circulation. J Clim 24:762-777

Fujibe F (2015) Relationship between Interannual Variations of Extreme Hourly Precipitation and Air/Sea-Surface Temperature in Japan. SOLA 11:5-9 doi:10.2151/sola.2015-002

Hand R, Keenlyside N, Omrani N-E, Latif M (2014) Simulated response to inter-annual SST variations in the Gulf Stream region. Clim Dyn 42:715-731

Hoskins BJ, Valdes PJ (1990) On the existence of storm-tracks. J Atmos Sci 47:18541864

Huffman GJ et al. (2007) The TRMM Multisatellite Precipitation Analysis (TMPA): Quasi-Global, Multiyear, Combined-Sensor Precipitation Estimates at Fine Scales. Journal of Hydrometeorology 8:38-55 doi:10.1175/JHM560.1

Iizuka S (2010) Simulations of wintertime precipitation in the vicinity of Japan: Sensitivity to fine-scale distributions of sea surface temperature. Journal of Geophysical Research: Atmospheres 115:D10107 doi:10.1029/2009jd012576

Isobe A, Kako Si (2012) A Role of the Yellow and East China Seas in the Development of Extratropical Cyclones in Winter. J Clim 25:8328-8340

Joyce TM, Kwon Y-O, Yu L (2009) On the Relationship between Synoptic Wintertime Atmospheric Variability and Path Shifts in the Gulf Stream and the Kuroshio Extension. J Clim 22:3177-3192 doi:10.1175/2008jcli2690.1 
Kako S, Nakagawa T, Takayama K, Hirose N, Isobe A (2016) Impact of Changjiang River Discharge on Sea Surface Temperature in the East China Sea. J Phys Oceanogr 46:1735-1750 doi:doi:10.1175/JPO-D-15-0167.1

Kamiguchi K, Arakawa O, Kitoh A, Yatagai A, Hamada A, Yasutomi N (2010) Development of APHRO_JP, the first Japanese high-resolution daily precipitation product for more than 100 years. Hydrological Research Letters 4:60-64

Kato T (1998) Numerical simulation of the band-shaped torrential rain observed over southern Kyushu, Japan on 1 August 1993. J Meteorol Soc Jpn 76:97-128

Kawai Y, Moteki Q, Kuwano-Yoshida A, Enomoto T, Manda A, Nakamura H (2017) Impact Propagation of Radiosonde Data Assimilation over the Kuroshio and Kuroshio Extension: Case Study on the Early Summer (Baiu) in 2012. J Meteorol Soc Jpn 95:71-90 doi:10.2151/jmsj.2017-004

Kawase $\mathrm{H}$ et al. (2009) Intermodel variability of future changes in the Baiu rainband estimated by the pseudo global warming downscaling method. Journal of Geophysical Research: Atmospheres 114:D24110 doi:10.1029/2009JD011803

Kelly KA, Small RJ, Samelson RM, Qiu B, Joyce TM, Kwon Y-O, Cronin MF (2010) Western Boundary Currents and Frontal Air-Sea Interaction: Gulf Stream and Kuroshio Extension. J Clim 23:5644-5667 doi:10.1175/2010jcli3346.1

Kida S et al. (2015) Oceanic fronts and jets around Japan: a review. J Oceanogr 71:469497 doi:10.1007/s10872-015-0283-7

Kwon M, Jhun J-G, Wang B, An S-I, Kug J-S (2005) Decadal change in relationship between east Asian and WNP summer monsoons. Geophys Res Lett 32:L16709 doi:10.1029/2005GL023026

Liu J-W, Xie S-P, Yang S, Zhang S-P (2016) Low-Cloud Transitions across the Kuroshio Front in the East China Sea. J Clim 29:4429-4443

Liu WT, Xie X, Niiler PP (2007) Ocean-Atmosphere Interaction over Agulhas Extension Meanders. J Clim 20:5784-5797 doi:10.1175/2007jcli1732.1

Ma X et al. (2017) Importance of Resolving Kuroshio Front and Eddy Influence in Simulating the North Pacific Storm Track. J Clim 30:1861-1880

Manda A et al. (2014) Impacts of a warming marginal sea on torrential rainfall organized under the Asian summer monsoon. Sci Rep 4 doi:10.1038/srep05741

Masunaga R, Nakamura H, Miyasaka T, Nishii K, Tanimoto Y (2015) Separation of Climatological Imprints of the Kuroshio Extension and Oyashio Fronts on the Wintertime Atmospheric Boundary Layer: Their Sensitivity to SST Resolution Prescribed for Atmospheric Reanalysis. J Clim 28:1764-1787

Maximenko N et al. (2009) Mean Dynamic Topography of the Ocean Derived from Satellite and Drifting Buoy Data Using Three Different Techniques. J Atmos Ocean Technol 26: 1910-1919

Minobe S, Kuwano-Yoshida A, Komori N, Xie SP, Small RJ (2008) Influence of the Gulf Stream on the troposphere. Nature 452:206-209 doi:10.1038/nature06690 
Minobe S, Miyashita M, Kuwano-Yoshida A, Tokinaga H, Xie S-P (2010) Atmospheric Response to the Gulf Stream: Seasonal Variations. J Clim 23:3699-3719

Nakamura H, Nishina A, Minobe S (2012) Response of Storm Tracks to Bimodal Kuroshio Path States South of Japan. J Clim 25:7772-7779

Nakamura H, Sampe T, Goto A, Ohfuchi W, Xie S-P (2008) On the importance of midlatitude oceanic frontal zones for the mean state and dominant variability in the tropospheric circulation. Geophys Res Lett 35 doi:10.1029/2008g1034010

Nakamura M, Yamane S (2010) Dominant Anomaly Patterns in the Near-Surface Baroclinicity and Accompanying Anomalies in the Atmosphere and Oceans. Part II: North Pacific Basin. J Clim 23:6445-6467 doi:10.1175/2010jcli3017.1

Ninomiya K (1984) Characteristics of Baiu Front as a Predominant Sub-Tropical Front in the Summer Northern Hemisphere. J Meteorol Soc Jpn 62:880-894

Ninomiya K, Shibagaki Y (2003) Cloud System Families in the Meiyu-Baiu Front Observed during 1-10 July 1991. J Meteorol Soc Jpn 81:193-209

O’Neill LW, Esbensen SK, Thum N, Samelson RM, Chelton DB (2010) Dynamical Analysis of the Boundary Layer and Surface Wind Responses to Mesoscale SST Perturbations. J Clim 23:559-581

O'Reilly CH, Czaja A (2014) The response of the Pacific storm track and atmospheric circulation to Kuroshio Extension variability. Quarterly Journal of the Royal Meteorological Society:in press doi:10.1002/qj.2334

Ogata T, Johnson SJ, Schiemann R, Demory M-E, Mizuta R, Yoshida K, Arakawa O (2017) The resolution sensitivity of the Asian summer monsoon and its inter-model comparison between MRI-AGCM and MetUM. Clim Dyn:1-17

Parfitt R, Czaja A, Minobe S, Kuwano-Yoshida A (2016) The atmospheric frontal response to SST perturbations in the Gulf Stream region. Geophys Res Lett 43:2016GL067723 doi:10.1002/2016GL067723

Reynolds RW, Smith TM, Liu C, Chelton DB, Casey KS, Schlax MG (2007) Daily HighResolution-Blended Analyses for Sea Surface Temperature. J Clim 20:5473-5496

Saha S et al. (2010) The NCEP Climate Forecast System Reanalysis. Bull Amer Meteor Soc 91:1015-1057 doi:10.1175/2010bams3001.1

Sampe T, Xie S-P (2010) Large-Scale Dynamics of the Meiyu-Baiu Rainband: Environmental Forcing by the Westerly Jet. J Clim 23:113-134

Sasaki YN, Minobe S, Asai T, Inatsu M (2012) Influence of the Kuroshio in the East China Sea on the Early Summer (Baiu) Rain. J Clim 25:6627-6645

Shibagaki Y, Ninomiya K (2005) Multi-scale Interaction Processes Associated with Development of a Sub-Synoptic-Scale Depression on the Meiyu-Baiu Frontal Zone. J Meteorol Soc Jpn 83:219-236 doi:10.2151/jmsj.83.219

Small RJ, Tomas RA, Bryan FO (2014) Storm track response to ocean fronts in a global high-resolution climate model. Clim Dyn 43:805-828 
Small RJ et al. (2008) Air-sea interaction over ocean fronts and eddies. Dyn Atmos Oceans 45:274-319 doi:10.1016/j.dynatmoce.2008.01.001

Smith BL, Yuter SE, Neiman PJ, Kingsmill DE (2010) Water Vapor Fluxes and Orographic Precipitation over Northern California Associated with a Landfalling Atmospheric River. Mon Wea Rev 138:74-100 doi:10.1175/2009mwr2939.1

Taguchi B, Nakamura H, Nonaka M, Komori N, Kuwano-Yoshida A, Takaya K, Goto A (2012) Seasonal Evolutions of Atmospheric Response to Decadal SST Anomalies in the North Pacific Subarctic Frontal Zone: Observations and a Coupled Model Simulation. J Clim 25:111-139 doi:10.1175/JCLI-D-11-00046.1

Tochimoto E, Kawano T (2012) Development Processes of Baiu Frontal Depressions. SOLA 8:9-12 doi:10.2151/sola.2012-003

Tokinaga H, Tanimoto Y, Xie S-P, Sampe T, Tomita H, Ichikawa H (2009) Ocean Frontal Effects on the Vertical Development of Clouds over the Western North Pacific: In Situ and Satellite Observations. J Clim 22:4241-4260

Tomita H, Kubota M, Cronin MF, Iwasaki S, Konda M, Ichikawa H (2010a) An assessment of surface heat fluxes from J-OFURO2 at the KEO and JKEO sites. J Geophys Res 115 doi:10.1029/2009jc005545

Tomita T, Nonaka M, Yamaura T (2010b) Interannual variability in the subseasonal northward excursion of the Baiu front. Int J Climatol 30:2205-2216

Tsunematsu N, Dairaku K, Hirano J (2013) Future changes in summertime precipitation amounts associated with topography in the Japanese islands. Journal of Geophysical Research: Atmospheres 118:4142-4153 doi:10.1002/jgrd.50383

Wu L et al. (2012) Enhanced warming over the global subtropical western boundary currents. Nat Clim Chang 2:161-166 doi:10.1038/nclimate1353

Xie S-P, Hafner J, Tanimoto Y, Liu WT, Tokinaga H, Xu H (2002) Bathymetric effect on the winter sea surface temperature and climate of the Yellow and East China Seas. Geophys Res Lett 29:2228 doi:10.1029/2002GL015884

$\mathrm{Xu} \mathrm{H}, \mathrm{Xu}$ M, Xie S-P, Wang Y (2011) Deep atmospheric response to the spring Kuroshio over the East China Sea. J Clim 24:4959-4972

$\mathrm{Xu}$ M, Xu H, Ren H (2017) Influence of Kuroshio SST front in the East China Sea on the climatological evolution of Meiyu rainband. Clim Dyn doi:10.1007/s00382-017-36812

Yang H, Lohmann G, Wei W, Dima M, Ionita M, Liu J (2016) Intensification and poleward shift of subtropical western boundary currents in a warming climate. J Geophys Res-Oceans 121:4928-4945 doi:10.1002/2015JC011513

Yang J, Liu Q, Xie S-P, Liu Z, Wu L (2007) Impact of the Indian Ocean SST basin mode on the Asian summer monsoon. Geophys Res Lett 34:L02708

Yim SY, Wang B, Xing W, Lu MM (2015) Prediction of Meiyu rainfall in Taiwan by multi-lead physical-empirical models. Clim Dyn 44:3033-3042 
Yu L, Jin X, Weller RA (2008) Multidecade Global Flux Datasets from the Objectively Analyzed Air-sea Fluxes (OAFlux) Project: Latent and sensible heat fluxes, ocean evaporation, and related surface meteorological variables. Woods Hole Oceanographic Institution, OAFlux Project Technical Report. OA-2008-01, 64pp. Woods Hole Massachusetts 



Figure 1. (a) Bathymetry of the study area. ECS and YS denote the East China Sea and Yellow Sea, respectively. (b) Climatology of sea surface temperature (SST; contour) with a contour interval of $1{ }^{\circ} \mathrm{C}$ and its gradients (color; $\times 10^{-2}{ }^{\circ} \mathrm{C}$ $\mathrm{km}^{-1}$ ) in June. (c) Climatology of the rain rate in June of the NCEP-CFSR reanalysis dataset. The gray closed circle indicates the position of Uchinoura at $31.278^{\circ} \mathrm{N}, 131.075^{\circ} \mathrm{E}$. 


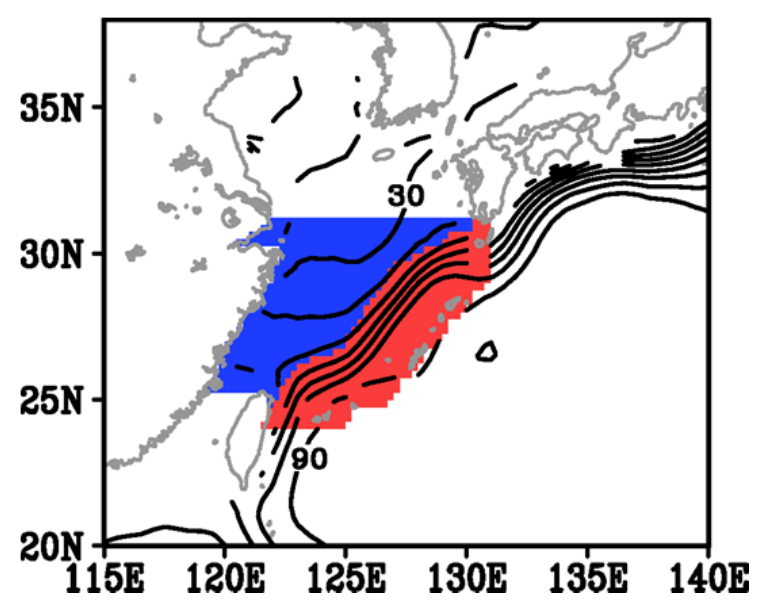

Figure 2. Definition of the Kuroshio region (red) and the continental shelf region (blue). Contours are the mean of sea surface height from 1992 to 2008 by Maximenko et al. (2009) with an interval of $10 \mathrm{~cm}$. 


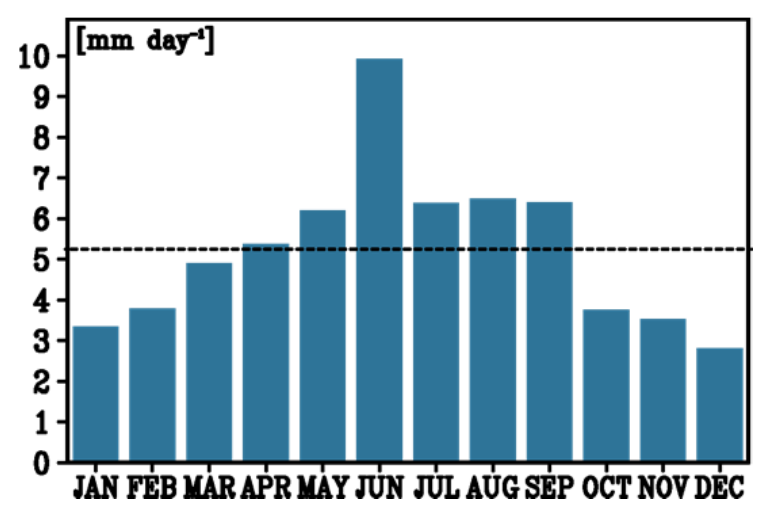

Figure 3. Monthly mean precipitation rate of the NCEP-CFSR reanalysis dataset averaged over the East China Sea $\left(25^{\circ} \mathrm{N}-35^{\circ} \mathrm{N}, 120^{\circ} \mathrm{E}-130^{\circ} \mathrm{E}\right)$. Dashed line denotes the corresponding annual mean precipitation rate. 


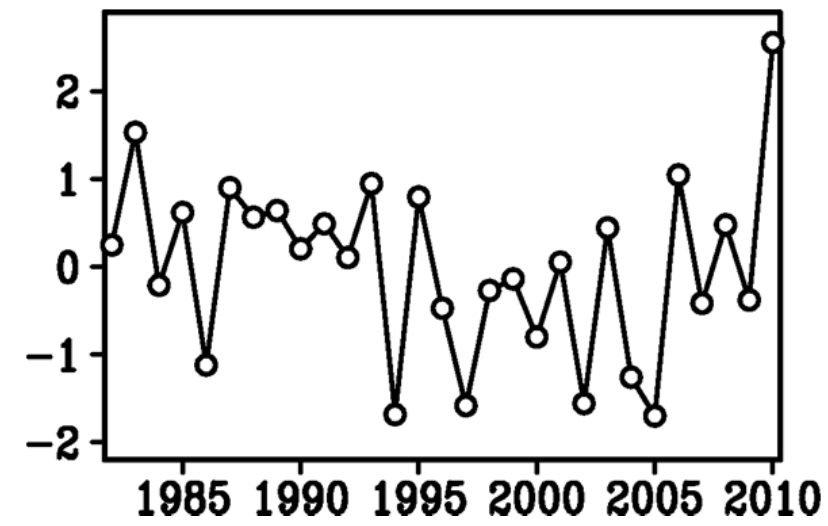

Figure 4. The SST front index from 1982 to 2010. The index is defined as the normalized difference of the SST between over the Kuroshio (red in Fig. 2) minus over the continental shelf (blue in Fig. 2). 



Figure 5. Regression coefficients of SST (a) in June, (b) in May, and (c) in April onto the SST front index from 1982 to 2010. Contours indicate the regions where the corresponding correlations are significant at the $90 \%$ confidence level. 

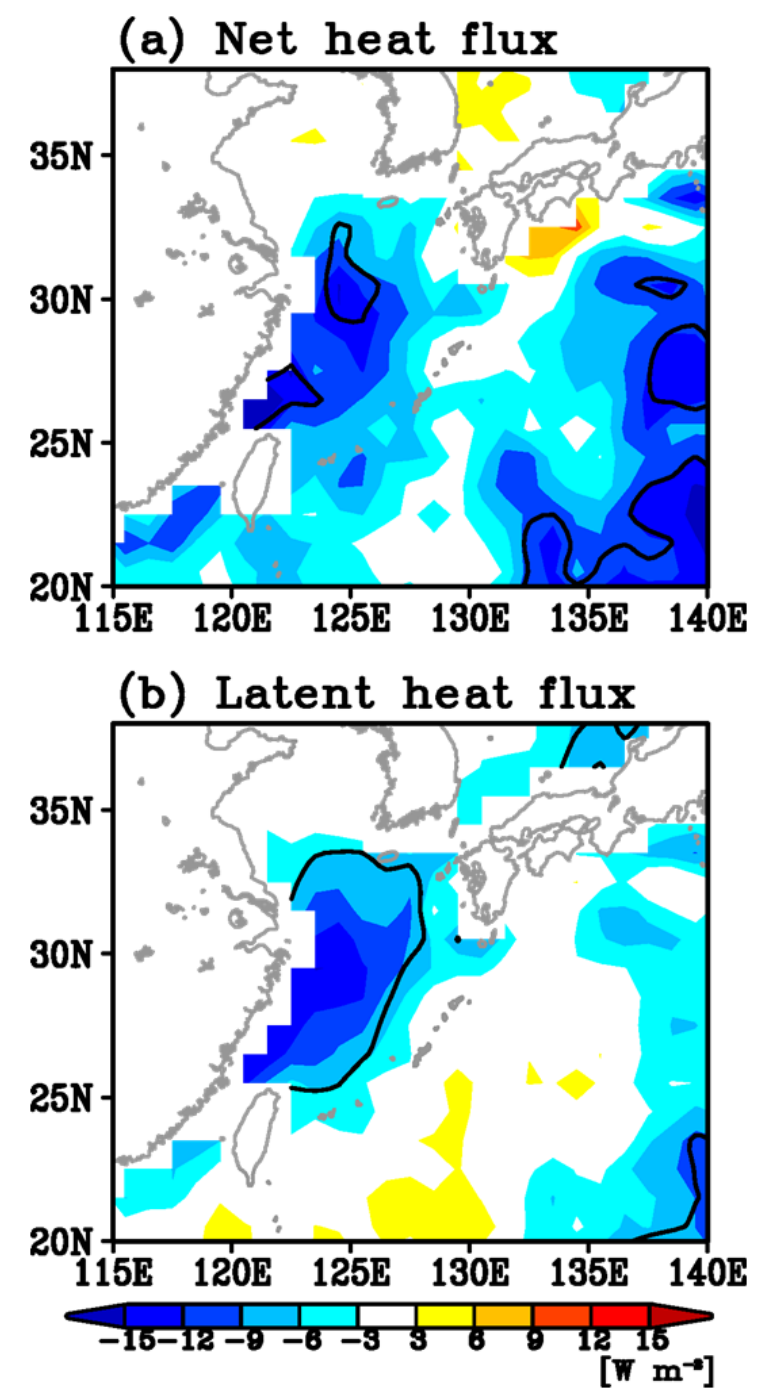

Figure 6. Same as Fig. 5a, but for (a) the net heat flux and (b) the latent heat flux of the J-OFURO dataset from 1988 to 2008 (upward positive). 


\section{(a) NCEP-CFSR}

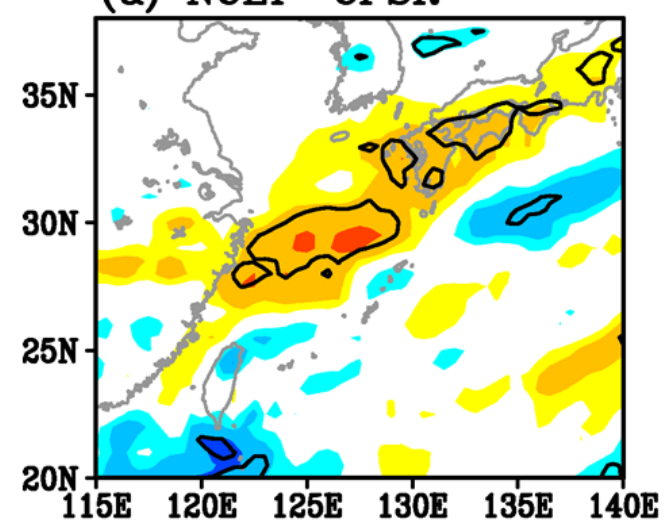

(b) TRMM3B43


(d) NCEP-CFSR before 1997

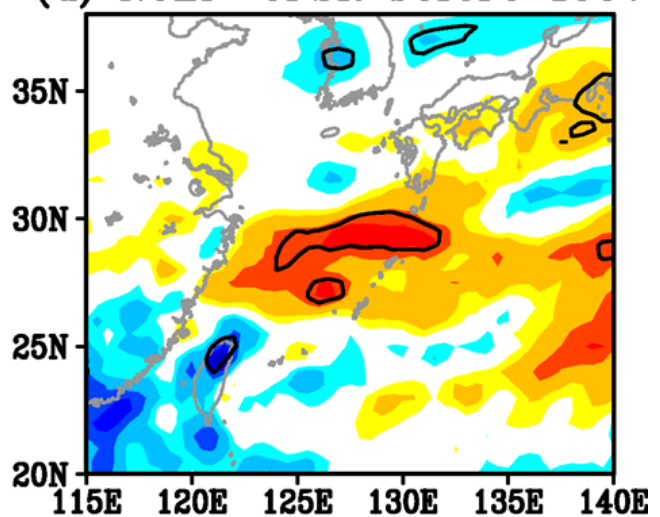

(e) NCEP-CFSR after 1998
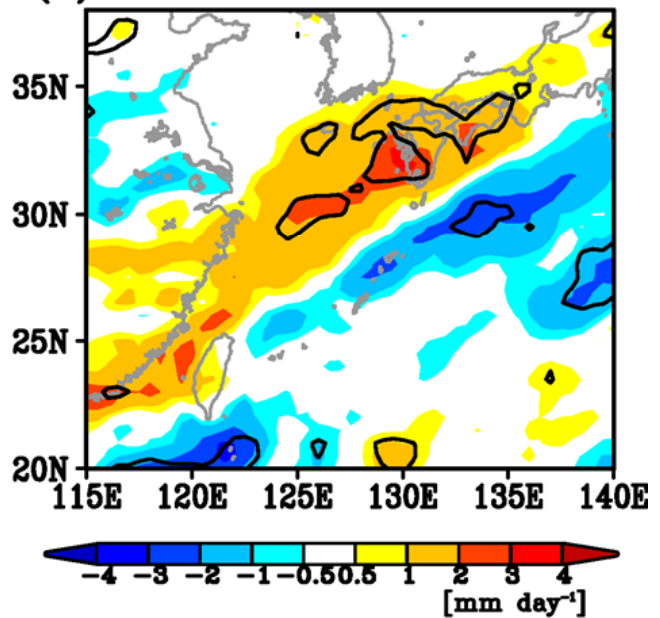

Figure 7. Same as Fig. 5a, but for the precipitation rate of (a) the NCEP-CFSR reanalysis dataset from 1982 to 2010, (b) the TRMM3B43 dataset from 1998 to 2010, (c) the APHRO-JP dataset from 1982 to 2010, and (d) and (e) the NCEP-CFSR reanalysis dataset from 1982 to 1997, and from 1998 to 2010, respectively. 


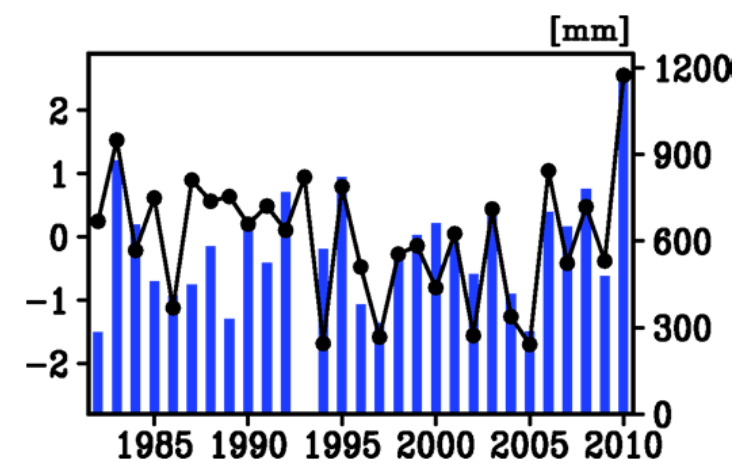

Figure 8. The precipitation at Uchinoura $\left(31.278^{\circ} \mathrm{N}, 131.075^{\circ} \mathrm{E}\right.$; see Fig. 1c) in June (blue; right axis) and the SST front index (black; left axis). The precipitation data is from the Automated Meteorological Data Acquisition System (AMeDAS) rain-gauge data provided by the Japan Meteorological Agency. The precipitation value in 1993 is missing. 

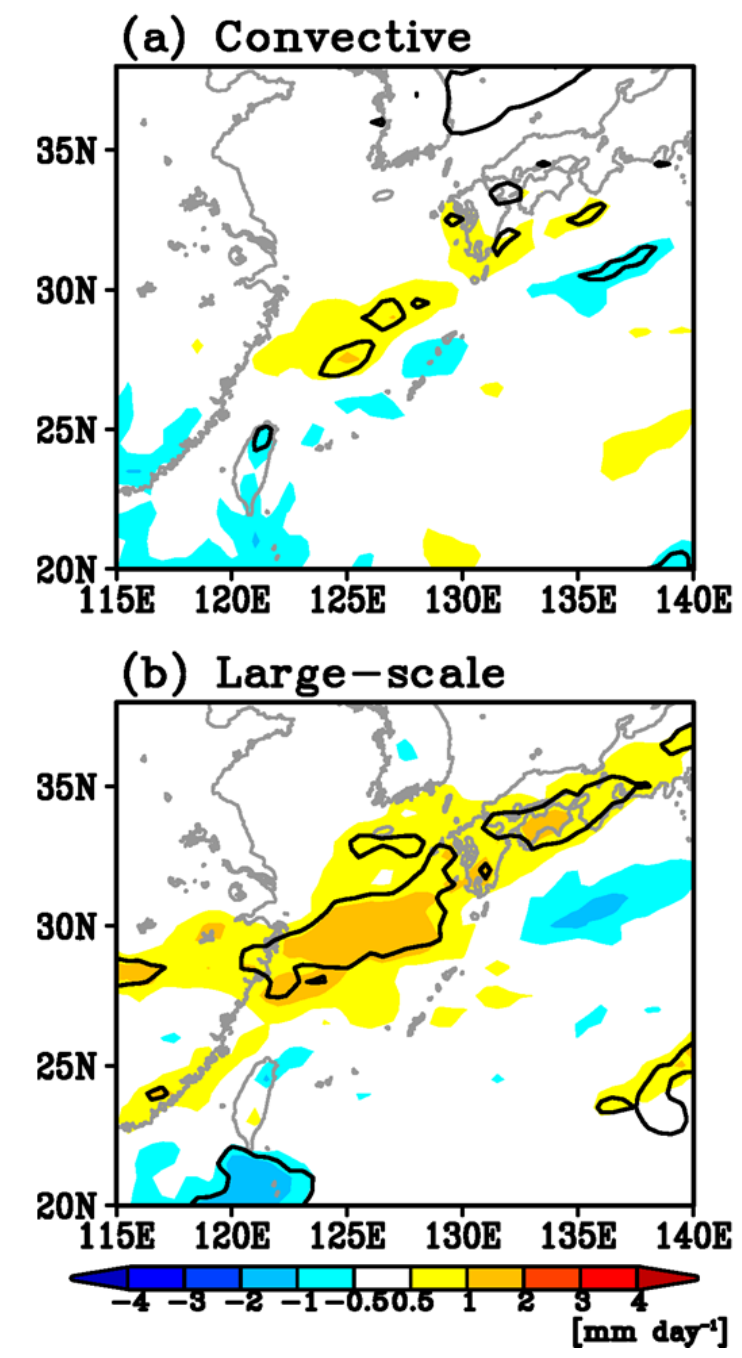

Figure 9. Same as Fig. 5a, but for (a) the convective precipitation rate and (b) the large-scale precipitation rate of the NCEP-CFSR reanalysis dataset from 1982 to 2010. 

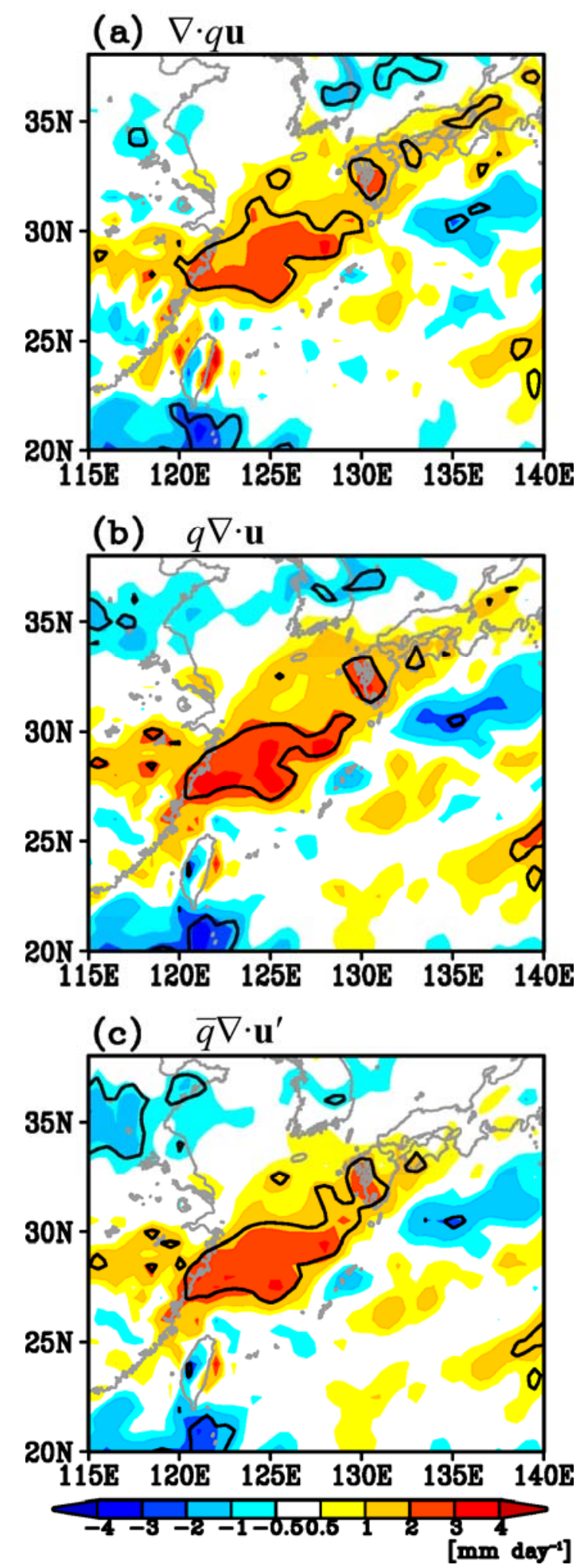

Figure 10. Same as Fig. 5a, but for vertical integration of (a) the convergence of moisture flux, (b) the product of specific humidity and horizontal wind convergence, and (c) the product of climatological specific humidity and horizontal wind convergence of the NCEP-CFSR reanalysis dataset from 1982 to 2010. 



Figure 11. (a) Climatology of F925 (the product of the relative vorticity and magnitude of horizontal the temperature gradient at $925 \mathrm{hPa}$ normalized by a typical scale of temperature gradient $(1 \mathrm{~K} / 100 \mathrm{~km})$ and the Coriolis parameter at $30^{\circ} \mathrm{N}$ ) of the NCEP-CFSR reanalysis dataset. (b) Same as Fig. 5a, but for F925 times ten of the NCEP-CFSR reanalysis dataset from 1982 to 2010. 


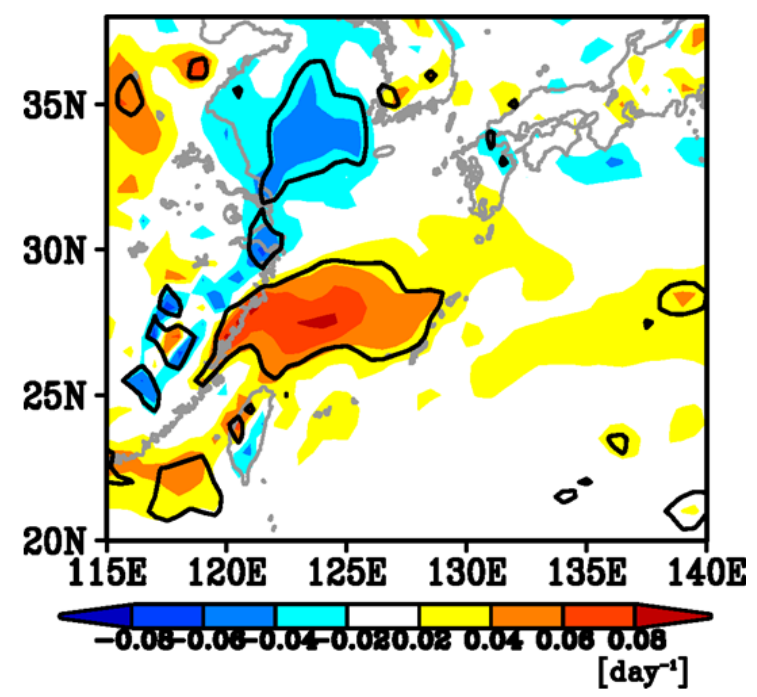

Figure 12. Same as Fig. 5a, but for the Eady growth rate at $925 \mathrm{hPa}$ of the NCEP-CFSR reanalysis dataset from 1982 to 2010. 


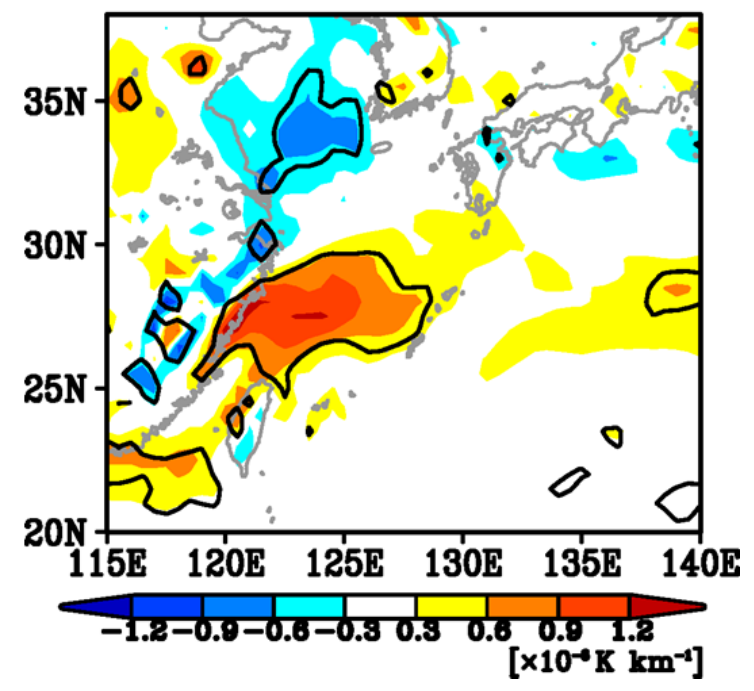

Figure 13. Same as Fig. 5a, but for the magnitude of the horizontal temperature gradient at $925 \mathrm{hPa}$ of the NCEP-CFSR reanalysis dataset from 1982 to 2010 . 


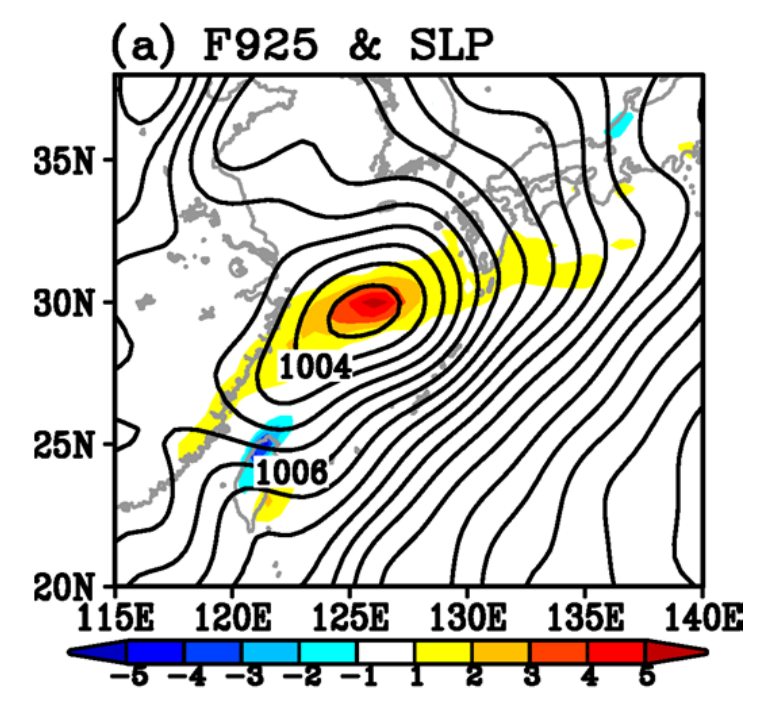

(b) Rain rate anomaly

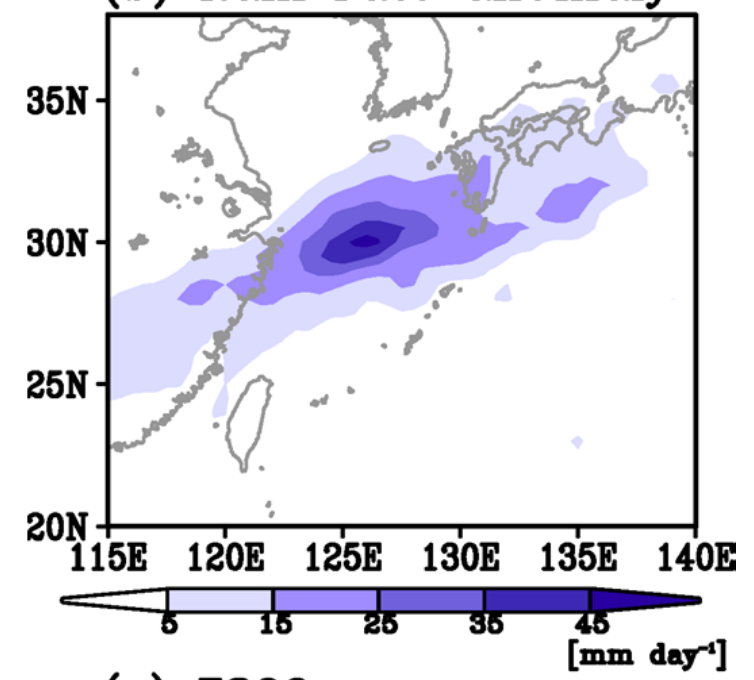

(c) $\mathrm{Z300}$

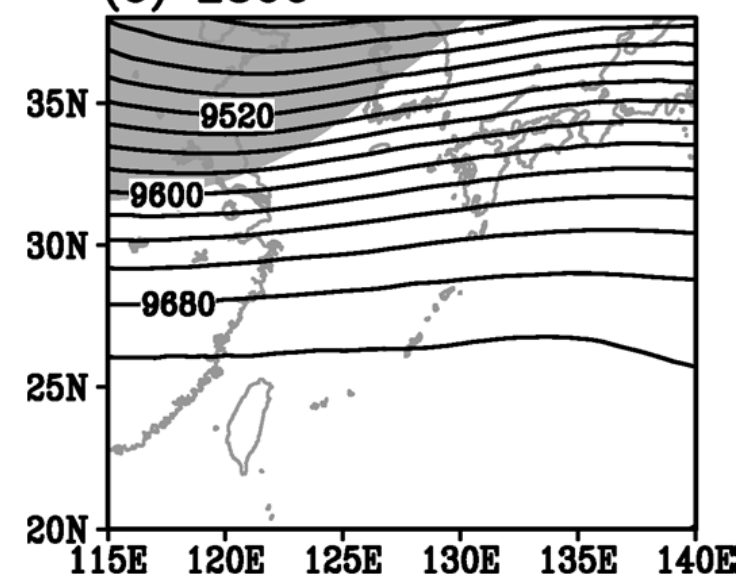

Figure 14. Composites of (a) F925 (color) and SLP (contour; hPa), (b) rain rate anomaly from the monthly climatology, (c) $300 \mathrm{hPa}$ geopotential height (contour, meter), when $F 925$ at $30^{\circ} \mathrm{N}, 126^{\circ} \mathrm{E}$ exceeds 2 and takes a maximum within plus and minus 2 days. Shading in panel (c) denotes the regions where the corresponding anomaly of $300 \mathrm{hPa}$ geopotential height is smaller than -20 meter. 